\title{
Enraizamento de miniestacas de Enterolobium contortisiliquum em garrafas PET
}

Teresa Aparecida Soares de Freitas ${ }^{1}$

Dêvisson Antônio Leal Pimenta²

Andrea Vita Reis Mendonça ${ }^{3}$

\section{Resumo}

O objetivo do trabalho foi avaliar o uso de miniestufas de garrafas PET para enraizamento de miniestacas de Enterolobium contortisiliquum. Foram instalados dois experimentos no viveiro. No primeiro experimento, foram preparadas 72 miniestacas, sendo 36 mergulhadas em solução de AIB na concentração de $2.000 \mathrm{mg} \mathrm{L}^{-1}$ e 36 mergulhadas em água por 60 segundos e estaqueadas nas garrafas com substrato comercial. Após 30 dias, foram quantificadas miniestacas vivas com formação de calos, miniestacas vivas com raiz e miniestacas mortas. No segundo experimento, foram utilizadas miniestacas caulinares e foliares de $5 \mathrm{~cm}$ sem o uso do hormônio, pois não foi verificada diferença de enraizamento no primeiro experimento. As 30 miniestacas caulinares e 30 foliares foram confeccionadas e estaqueadas em garrafas PET e avaliadas por 30 dias quanto à sobrevivência, número de raízes emitidas e comprimento das raízes. Após as avaliações, elas foram transplantadas para tubetes de $180 \mathrm{~cm}^{3}$ para avaliar o desenvolvimento das mudas, sendo mantidas por 60 dias no viveiro, avaliando-se altura da parte aérea e diâmetro do colo. Os experimentos foram instalados em um ambiente de enraizamento, em delineamento inteiramente casualizado e dois tratamentos. Para o primeiro experimento, os tratamentos foram com e sem hormônios, e os dados foram analisados pelo teste chi square; para o segundo experimento, foram dois tipos de miniestacas (caulinares e foliares), com análise dos dados pelo teste t (student) a 5\% de probabilidade. Após a realização dos experimentos, verificou-se que o uso de miniestufas confeccionadas com garrafas PET possibilitou o enraizamento de miniestacas de Enterolobium contortisiliquum independentemente do uso de hormônios, e as miniestacas caulinares formaram mudas de qualidade superior.

Palavras-chave: Miniestufas. Tamboril. Propagação vegetativa.

\section{Introdução}

A miniestaquia é uma técnica que surgiu a partir da estaquia convencional (FERRIANI et al., 2011) e vem sendo aplicada em grande escala, principalmente com a cultura do Eucalyptus spp. pelas empresas florestais (MORAES et al., 2014).

Para elevar o potencial de enraizamento, é usual a aplicação de reguladores de crescimento como o AIB no momento do estaqueamento, no entanto, muitas espécies dispensam o uso de hormônios exógenos, quando se utiliza material juvenil. Além disso, o enraizamento de miniestacas pode ser influenciado pelo tipo de estaca utilizada e pelo ambiente de enraizamento. As estacas podem ser caulinares, foliares e radiculares (MORAES,D. et al., 2014). 0 ambiente adequado deve oferecer, de

1 Universidade Federal do Recôncavo da Bahia, professor. tas_freitas@hotmail.com. Rua Rui Barbosa, 710, Centro, Cruz das Almas (BA), Brasil, CEP: 44.380-000.

2 Universidade Federal do Recôncavo da Bahia, Engenharia Florestal. tony.leal17@gmail.com.

3 Universidade Federal do Recôncavo da Bahia, professor. andrea@ufrb.edu.br. 
forma balanceada, luz e umidade, fatores importantes para o desenvolvimento e transformação das estacas em mudas.

Muitas espécies são propagadas inicialmente em ambientes automatizados com temperatura e umidade relativa do ar controladas, o que encarece a produção, porém há alternativas como o uso de sistemas de controle mais simples que poderão proporcionar resultados satisfatórios com custos reduzidos (BRODANI et al., 2008).

$\mathrm{Na}$ atualidade existem problemas sérios com poluição em função de descarte inadequado de material que, muitas vezes, demandam anos, décadas ou até séculos para se degradarem no ambiente. As garrafas PETs, que geralmente são encontradas nos ambientes de forma inadequada, vêm sendo testadas por alguns pesquisadores como ambiente de enraizamento de estacas de maracujá, goiaba, lichia e carambola, indicando ser uma técnica que poderá ser utilizada na propagação vegetativa por pequenos produtores por necessitar de poucos recursos para sua implantação (MOREIRA et al., 2015; REZENDE et al., 2005; MILHEM et al., 2014; APARECIDO et al., 2013; MORAES, A. et al., 2014).

De acordo com Rezende et al. (2005), essa técnica pode dispensar o uso de estruturas mais complexas e onerosas, possuindo bom desempenho se comparado com o investimento inicial que essas exigem, além de possibilitar a dispensa de vários fatores como infraestrutura, casa de vegetação, energia, eletricidade e economia de água. No entanto, são necessários estudos sobre o comportamento de outras espécies em relação à eficiência desse método, uma vez que cada espécie apresenta sua particularidade.

Algumas espécies florestais nativas já possuem estudos sobre técnicas de propagação vegetativa, porém, considerando a alta diversidade no Brasil, poucas espécies foram estudadas, uma vez que a maioria dos estudos nesta área é concentrada em espécies exóticas. Além disso, as estruturas utilizadas para a realização dos estudos são altamente tecnificadas, dificultando o uso dessas por pequenos produtores.

Uma das espécies nativas para a qual ainda não há dados na literatura envolvendo técnicas de propagação vegetativa é a Enterolobium contortisiliquum (Vell.) Morong. Uma arbórea de crescimento rápido e grande porte, de ampla distribuição geográfica no Brasil, também encontrada em outros países como Argentina, Bolívia, Colômbia, Paraguai, Peru e Uruguai e conhecida popularmente como tamboril, orelha de macaco, orelha de negro, entre outros (LORENZI, 2008). Sua madeira é usada para fabricar barcos e canoas de tronco inteiro, brinquedos, compensados e armações de móveis (LORENZI, 2008). É uma espécie que apresenta certa tolerância a metais pesados, sendo promissora para pesquisas que objetivem a revegetação nessas áreas (ANDRADE, 2005; TRANNIN; MOREIRA; SIQUEIRA, 2001).

Assim, este trabalho tem como objetivo avaliar o uso de miniestufas confeccionadas de garrafas PET, como alternativa de um sistema mais simplificado para propagação vegetativa do Enterolobium contortisiliquum por meio da miniestaquia.

\section{Material e métodos}

Os experimentos foram realizados no viveiro de produção de mudas florestais da Universidade Federal do Recôncavo da Bahia, em Cruz das Almas, Bahia.

Para realização dos dois experimentos foi confeccionado um minijardim multiclonal para fornecimento das brotações. As sementes de Enterolobium contortisiliquum (Vell.) Morong foram semeadas em tubetes de 180 e $280 \mathrm{~cm}^{3}$ em abril de 2014 e, após 60 dias, quando as mudas estavam 
com pelo menos $10 \mathrm{~cm}$ de altura, realizou-se a poda com auxílio de uma tesoura de poda a $8 \mathrm{~cm}$ da base das mudas para obtenção do minijardim, deixando em cada minicepa um par de folhas cortadas ao meio em sentido oposto para realizar fotossíntese e facilitar a emissão de brotações. 0 minijardim foi composto por 40 minicepas.

Após 30 dias da poda, foram realizadas sete coletas sucessivas de miniestacas a cada 15 dias e, em seguida, houve uma pausa de 60 dias, como forma de obtenção de maior número de brotações de maior comprimento para condução dos experimentos.

O substrato para todas as fases (condução do minijardim, enraizamento das miniestacas e produção de mudas via miniestaquia) foi um comercial composto por casca de pinus bioestabilizada, vermiculita, moinha de carvão vegetal, água e espuma fenólica, e a adubação foi realizada com adubo de liberação controlada (NPK 14-14-14) na dose de 8g por quilo de substrato.

Durante o período de realização dos experimentos, as minicepas foram adubadas semanalmente com fertilizante foliar para pronto uso com macro e micronutrientes, na quantidade de $5 \mathrm{~mL}$ por minicepas.

\section{Experimento 1:}

Para verificar a necessidade de utilização de hormônios para emissão de raízes, foram preparadas 72 miniestacas, em que 36 foram mergulhadas em uma solução de AIB na concentração de $2.000 \mathrm{mg} \mathrm{L}^{-1}$ e 36 mergulhadas em água pura por 60 segundos e, em seguida, estaqueadas nas miniestufas (garrafas PET) com o mesmo substrato utilizado na confecção do minijardim, descrito anteriormente. Foram estaqueadas quatro miniestacas por garrafa. Após 30 dias, foram quantificadas miniestacas vivas com formação de calos, miniestacas vivas com raiz e miniestacas mortas.

As coletas das brotações para confecção das miniestacas foram realizadas com auxílio de uma tesoura de poda no final da tarde e levadas para o laboratório, acondicionadas em uma bandeja plástica com água para serem preparadas e, em seguida, estaqueadas.

Para o ambiente de enraizamento, foram utilizadas garrafas de poliestireno tetraftalato incolores de um litro (garrafas PET), que foram lavadas, cortadas ao meio e furadas na parte inferior para escorrer o possível excesso de água do substrato sendo preenchidas com $5 \mathrm{~cm}$ de substrato comercial úmido. Após o estaqueamento, as partes das garrafas foram encaixadas, lacradas e levadas para área do viveiro, sendo irrigadas a cada dois dias, abrindo-se a tampa da garrafa e borrifando $200 \mathrm{ml}$ de água/garrafa por irrigação.

O experimento foi instalado em delineamento inteiramente casualizado, com dois tratamentos (com e sem hormônio) e um ambiente de enraizamento (garrafas PET), sendo os dados analisados pelo teste chi square a $5 \%$ de probabilidade.

\section{Experimento 2:}

Neste experimento foram utilizadas miniestacas caulinares e foliares de $5 \mathrm{~cm}$ sem o uso do hormônio, pois não foi verificada diferença de enraizamento no primeiro experimento. As miniestacas foram coletadas do mesmo minijardim após quatro meses de repouso. Foram confeccionadas 30 miniestacas caulinares e 30 foliares e estaqueadas três por garrafa (miniestufas), sendo mantidas por 30 dias para então serem avaliadas quanto à sobrevivência, número de raízes emitidas e comprimento das raízes em cada miniestaca. Em seguida, essas miniestacas com raiz foram transplantadas para tubetes de $180 \mathrm{~cm}^{3}$ para, após 60 dias, serem avaliadas quanto ao crescimento das mudas em diâmetro do colo e altura da parte aérea. 
O preparo das miniestufas, a coleta das brotações para confecção das minestacas, o estaqueamento e as irrigações foram realizados como descrito no experimento 1 .

0 experimento foi instalado em delineamento inteiramente casualizado, com dois tratamentos (miniestacas caulinares e miniestacas foliares) e um ambiente de enraizamento (miniestufas de garrafas $\mathrm{PET}$ ), sendo os dados analisados pelo teste $t$ (student) a $5 \%$ de probabilidade.

\section{Resultados e discussão}

Como pode ser observado na Tabela 1, o uso de hormônio não influenciou a sobrevivência e o enraizamento das miniestacas de Enterolobium contortisiliquum, e o ambiente de enraizamento permitiu que aproximadamente $60 \%$ das miniestacas se mantivessem vivas neste período de avaliação.

Tabela 1. Número de miniestacas vivas com formação de raízes (MVR), número de miniestacas vivas com formação de calo (MVC) e número de miniestacas mortas (MM) com presença ou ausência de hormônios em miniestufas de garrafa PET, de Enterolobium contortisiliquum

\begin{tabular}{cccc}
\hline Tratamentos & MVR & MVC & MM \\
\hline Com hormônio & $9(9)$ & $13(12)$ & $14(15)$ \\
Sem hormônio & $9(9)$ & $11(12)$ & $16(15)$ \\
$X^{2}$ calculado & & 0,3 & \\
$X^{2}$ tabelado & & 5,99 & \\
\hline
\end{tabular}

Valor esperado entre parênteses (). Teste chi square a $5 \%$ de probabilidade

Fonte: Elaboração dos autores (2016)

Vários autores indicam que o material juvenil oriundo de mudas produzidas por sementes dispensa o uso de reguladores vegetais para estimular a indução do enraizamento. Dias et al. (2012b), Xavier et al. (2003a), Ferreira et al. (2010) e Silva et al. (2010) trabalharam respectivamente com as espécies Anadenanthera macrocarpa, Cedrela fissilis, Sapium glandulatum e Colaphyllum brasiliense e encontraram resultados semelhantes como no presente trabalho.

De acordo com Dias et al. (2012a), o uso de material juvenil, como miniestacas, pode dispensar a aplicação de hormônio exógeno, pois esse material apresenta balanço hormonal endógeno favorável ao enraizamento. Para espécies florestais, o uso de hormônio exógeno tem como finalidade aumentar o número de raízes por miniestacas, além de acelerar sua formação e uniformizar o enraizamento (CARVALHO et al., 2005). Assim, esse hormônio pode ser dispensado ou utilizado em baixíssimas concentrações (XAVIER; WENDLING; SILVA, 2009).

$\mathrm{Na}$ Tabela 2, observa-se que $53 \%$ das miniestacas caulinares emitiram raízes, enquanto apenas $16,67 \%$ das miniestacas confeccionadas com folha foram capazes de emitir raízes. No entanto, não houve diferença em relação ao número de raízes e ao comprimento de raízes em função do tipo de miniestacas utilizadas (Tabela 3).

Tabela 2. Número de miniestacas enraizadas e percentagem de enraizamento de miniestacas de diferentes propágulos de Enterolobium contortisiliquum obtidas a partir de minijardim multiclonal, 30 dias após 0 estaqueamento em miniestufas de garrafa PET

\begin{tabular}{ccc}
\hline Tratamento & $\mathbf{N}^{\circ}$ de miniestacas enraizadas & \% de enraizamento \\
\hline Miniestacas de folhas & 5 & 16,67 \\
Miniestacas caulinares & 16 & 53,33 \\
\hline
\end{tabular}

Fonte: Elaboração dos autores (2016) 
O enraizamento de $53 \%$ das miniestacas caulinares no presente trabalho é bastante expressivo, principalmente em função do ambiente adotado para o enraizamento. Os pequenos produtores que trabalham em escalas menores e são dotados de baixo recurso financeiro poderiam aplicá-los em sua propriedade. Isso se dá pelo fato de essa técnica demandar poucos recursos, se comparada ao enraizamento de miniestacas em câmara de nebulização, possibilitando grande economia de água e energia, uma vez que dispensa o uso de bombas d'água e infraestrutura como casa de vegetação (REZENDE et al., 2005).

A miniestufa de garrafas PET vem mostrando eficiência em vários trabalhos. Moreira et al. (2015) demonstraram que o uso do sistema de miniestufas com garrafa PET foi eficiente na proteção das estacas de maracujá, impedindo a troca de umidade entre o ambiente interno e externo. Além disso, os autores comentam que as miniestufas foram importantes na fase inicial de pegamento das miniestacas por fornecer condições fisiológicas mais propícias para o desenvolvimento das miniestacas devido à temperatura adequada e redução da transpiração, corroborando Milhem et al. (2014). Esses últimos autores afirmam que o uso de miniestufas de garrafas PET na propagação de goiabeira apresentaram condições para evitar a desidratação dos tecidos, embora esse sistema tenha obtido menor eficiência.

Apesar de as miniestacas de folhas terem apresentado baixo enraizamento em relação às miniestacas de caule, não houve diferença no número e comprimento das raízes entre os tipos de miniestacas como mostra a Tabela 3.

Tabela 3. Número de raízes e comprimento de raízes de miniestacas de diferentes propágulos de Enterolobium contortisiliquum obtidas a partir de minijardim multiclonal, 30 dias após o estaqueamento em miniestufas de garrafa PET

\begin{tabular}{ccc}
\hline Tratamentos & $\mathbf{N}^{\circ}$ de raízes & Comprimento de raízes \\
\hline Miniestacas de folhas & 3,8 a & $5,63 \mathrm{a}$ \\
Miniestacas de caule & 3,37 a & $8,3 \mathrm{a}$ \\
T calculado & 0,32 & 0,72 \\
T tabelado & 2,09 & 2,09 \\
\hline
\end{tabular}

Médias nas colunas não diferem pelo teste $\mathrm{t}$ (Student) a $5 \%$ de probabilidade

Fonte: Elaboração dos autores (2016)

Moraes D. et al. (2014), conduzindo o experimento em ambientes com nebulização intermitente, verificaram que não houve diferença no enraizamento em função dos tipos de propágulos utilizados de Toona ciliata. No entanto, com o uso do ambiente sem controle de umidade (em uma casa de vegetação simples, com irrigação manual duas vezes ao dia), o percentual de enraizamento em miniestacas foliares atingiu o máximo de $8 \%$, enquanto para as miniestacas caulinares, o enraizamento ficou entre 54 e $66 \%$.

Moreira et al. (2015) relatam que o uso de garrafas PET para propagação vegetativa de mudas de maracujá surgiu da busca de inovação tecnológica que visasse à melhoria do sistema de produção com melhor qualidade de mudas, além de redução dos custos. $E$, de acordo com os autores, além desses fatores, esse sistema apresentou eficiência na proteção da estaca, o que impediu a troca de umidade entre o ambiente interno e o externo.

No experimento conduzido por Almeida et al.(2008), foi utilizada câmara úmida confeccionada com caixa de amianto coberto com plástico polietileno transparente e sombrite $50 \%$, as estacas de Ixora coccínea apresentaram percentagem de enraizamento significativamente superior (66\%), mesmo esse método sendo mais simples que o enraizador convencional, com sistema de irrigação através 
de microaspersores, que obteve apenas $10 \%$ de estacas enraizadas. De acordo com os autores, as estacas dispostas na câmara úmida possivelmente apresentaram os melhores resultados devido à retenção de umidade que é proporcionada neste ambiente, o que está de acordo com Moreira et al. (2015) e também foi confirmado no presente trabalho.

Em relação à produção de mudas, após o enraizamento em garrafa PET, apesar de não haver diferença de enraizamento entre os tipos de mininestacas, houve diferença na produção de mudas (Tabela 4). As mudas provenientes de miniestacas caulinares obtiveram maiores altura e diâmetro 60 dias após a transferência das miniestacas para os tubetes em casa de vegetação com sombrite 50 \%.

Tabela 4. Altura e diâmetro de mudas Enterolobium contortisiliquum oriundas de miniestacas de folhas e caule 60 dias após o transplantio para tubete de $180 \mathrm{~cm}^{3}$

\begin{tabular}{ccc}
\hline Tratamentos & Altura & Diâmetro \\
\hline Miniestacas de folhas & $5,387 \mathrm{~b}$ & $2,44 \mathrm{~b}$ \\
Miniestacas de caule & $11,37 \mathrm{a}$ & $4,44 \mathrm{a}$ \\
T calculado & 3,2 & 4,9 \\
T tabelado & 2,11 & 2,11 \\
\hline
\end{tabular}

Médias nas colunas não diferem pelo teste t (Student) a $5 \%$ de probabilidade

Fonte: Elaboração dos autores (2016)

Betanin e Nienow (2010), trabalhando com Erythrina falcata, observaram maior enraizamento de miniestacas foliares quando comparadas às miniestacas caulinares sem folhas, no entanto, os autores relatam que apesar do sucesso no enraizamento de estacas foliares, nenhuma estaca emitiu brotação durante o período de realização do experimento, sugerindo a inexistência ou impossibilidade de as folhas formarem gemas vegetativas capazes de regenerarem uma planta. Por outro lado, no presente trabalho, apenas uma miniestaca de folha enraizada não sobreviveu até a fase final de produção de mudas, apesar de as miniestacas de folhas apresentarem baixa sobrevivência na fase de enraizamento.

Xavier, Santos e Oliveira (2003b) trabalhando com Cedrela fissilis também apresentaram resultados distintos aos obtidos, em que as mudas propagadas via miniestaquia foliar apresentaram total mortalidade no final de 90 dias, concluindo que para este tipo de propágulo não houve nenhuma resposta ao desenvolvimento e crescimento da parte aérea, mostrando a incapacidade dos tecidos vegetais de desenvolver novos meristemas caulinares.

Os mesmos autores observaram que, aos 60 dias, a altura e o diâmetro das mudas de Cedrela fissilis provenientes de miniestacas foliares também apresentaram crescimento inferior àquelas provenientes de miniestacas caulinares, o que igualmente foi observado no presente trabalho. No entanto, no final do ciclo de produção das mudas, aos 90 dias, essas não sobreviveram, diferenciando do presente trabalho em que as mudas provenientes de miniestacas foliares enraizadas deram origem a mudas no final da avaliação, porém mudas de qualidade inferior, não sendo interessante 0 uso de miniestacas de folhas para propagação dessa espécie nas condições em que o experimento foi conduzido.

\section{Conclusão}

O uso de miniestufas confeccionadas com garrafas PET possibilitou o enraizamento de miniestacas de tamboril independentemente da aplicação externa de hormônio enraizador. 
As miniestacas caulinares formaram mudas de qualidade superior em comparação às miniestacas de folhas quando enraizadas em miniestufas de garrafas PET.

\title{
Minicutting rooting of Enterolobium contortisiliquum in PET bottles
}

\begin{abstract}
This study aimed to evaluate the use of minigreenhouses of PET bottles for rooting cuttings of Enterolobium contortisiliquum. Two experiments were installed in a nursery. For the first experiment, 72 minicuttings were prepared, 36 dipped in AIB solution at a concentration of $2.000 \mathrm{mg} \mathrm{L}^{-1}$ and 36 soaked in water for 60 seconds and planted in bottles containing commercial substrate. After 30 days, the live minicuttings with callus formation, live minicuttings with roots and dead minicuttings were quantified. In the second experiment, it was used stem cuttings and leaf minicuttings of $5 \mathrm{~cm}$ without the use of the hormone, due to the fact that rooting difference was not verified in the first experiment. 30 stem minicuttings and 30 leaf minicuttings were obtained and planted in PET bottles. They were studied for 30 days, at which the survival rates, number of issued roots and their lengths were assessed. After the assessments, the seedlings were transplanted into $180 \mathrm{~cm}^{3}$ plastic tubes to evaluate their development, being held for 60 days in the nursery; the aerial part height and stem diameter were evaluated. The experiments were conducted in a rooting environment, in a completely randomized design, under two treatments. For the first experiment, the treatments were conducted with and without hormones and the data were analyzed by the chi square test; for the second experiment, two types of minicuttings (stem and leaf) were conducted and analyzed by t-test (student) at $5 \%$ of probability. It was found that the use of mini greenhouse made with PET bottles allowed the rooting of minicuttings of Enterolobium contortisiliquum without the need of using hormones, and the stem minicuttings formed seedlings of superior quality.
\end{abstract}

Keywords: Minigreenhouses. Tamboril. Vegetative propagation.

\section{Referências}

ALMEIDA, E. F. A.; LUZ, P. B. da; LESSA, M. A.; OLIVEIRA, M. V. C; PAIVA, P. D. O.; ALBUQUERQUE, C. J. B.; OLIVEIRA, M. V. C. de. Diferentes substratos e ambientes para enraizamento de mini-ixora (/xora coccinea 'compacta'). Ciência e Agrotecnologia, Lavras, v. 32, n. 5, p. 1449-1453. Disponível em: <http://www.scielo.br/pdf/cagro/v32n5/14.pdf>. Acesso em: 16 dez. 2015.

ANDRADE, J. C. M. Fitotransporte de metais em espécies arbóreas e arbustivas em aterro de resíduos sólidos urbanos (Rio de Janeiro). 2005. 263p. Tese (Doutorado em Engenharia Civil) - Universidade Federal do Rio de Janeiro, COPPE, Rio de Janeiro, 2005. Disponível em: < http://www.getres. ufrj.br/pdf/ANDRADE_JCM_05_t_D_geo.pdf>. Acesso em: 16 nov. 2015.

APARECIDO, L. E. O.; PENHA, E. T. S.; SOUZA, P. S. Avaliações de substratos no enraizamento das estacas de goiabeira em miniestufas de garrafas PET recicladas. Revista Agrogeoambiental, Pouso Alegre, v. 5, n. 1, p. 19-26, 2013. Disponível em: <http://agrogeoambiental.ifsuldeminas.edu.br/ index.php/Agrogeoambiental/article/view/456>. Acesso em: 16 nov. 2015. 
BETANIN, L.; NIENOW, A. A. Propagação vegetativa da corticeira-da-serra (Erythrina falcata Benth.) por estaquia caulinar e foliar. Semina: Ciências Agrárias, Londrina, v. 31, n. 4, p. 871-880, out./dez. 2010. Disponível em: <http://www.uel.br/revistas/uel/index.php/semagrarias/article/view/2513>. Acesso em: 16 dez. 2015.

BRONDANI, G. E.; ARAÚJO, M. A. de; WENDLING, I.; KRATZ, D. Enraizamento de miniestacas de Erva-Mate sob diferentes ambientes. Revista Pesquisa Florestal Brasileira, n. 57, p. 29-38, 2008. Disponível em: <http://pfb.cnpf.embrapa.br/pfb/index.php/pfb/article/view/70>. Acesso em: 16 dez. 2015.

CARVALHO, C. M.; CUNHA, R. J. P. ; RODRIGUES, J. D. Enraizamento de Estacas semilenhosas de Lichieira utilizando ácido indolbutírico. Revista Brasileira de Fruticultura. Jaboticabal, v. 27, n. 1, p. 95-97, 2005. Disponível em: <http://www.scielo.br/scielo.php?script=sci_arttext\&pid=S0100-29452005000100026>. Acesso em: 10 jul. 2016.

DIAS, P. C.; OLIVEIRA, L. S. de; XAVIER, A.; WENDLING, I. Estaquia e miniestaquia de espécies florestais lenhosas do Brasil. Pesquisa Florestal Brasileira. Colombo, v. 32, n. 72, p. 453-462, 2012. Disponível em: <http://pfb.cnpf.embrapa.br/pfb/index.php/pfb/article/view/388>. Acesso em: 16 dez. 2015.

DIAS, P. C.; XAVIER, A.; OLIVEIRA, L. S. de; PAIVA, H. N. de; CORREIA, A. C. G. Propagação vegetativa de progênies de meios-irmãos de angico-vermelho (Anadenanthera macrocarpa (Benth) Brenan) por miniestaquia. Revista Árvore. Viçosa, v. 36, n. 3, p. 389-399, 2012b. Disponível em: <http:// www.scielo.br/pdf/rarv/v36n3/v36n3a01.pdf>. Acesso em: 16 dez. 2015.

FERREIRA, B. G. A.; ZUFFELLATO-RIBAS, K. C.; WENDLING, I.; KOEHLER, H. S.; NOGUEIRA, A. C. Miniestaquia de Sapium glandulatum (Vell.) pax com o uso de ácido indolbutírico e ácido naftaleno acético. Ciência Florestal, Santa Maria. v. 20, n. 1, p. 19-31, 2010. Disponível em: <http:// cascavel.ufsm.br/revistas/ojs-2.2.2/index.php/cienciaflorestal/article/view/1758/1025>. Acesso em: 16 dez. 2015.

FERRIANI, A. P.; ZUfFELLATO-RIBAS, K. C.; HELM, C. V.; BOZA, A.; WENDLING, I.; KOEHLER, H. S. Produção de brotações e enraizamento de miniestacas de Piptocarpha angustifolia. Pesquisa Florestal Brasileira, Colombo. v. 31, n. 67, p. 257-264. 2011. Disponível em: <http://pfb.cnpf. embrapa.br/pfb/index.php/pfb/article/view/172>. Acesso em: 16 nov. 2015.

LORENZI, H. Árvores brasileiras: manual de identificação e cultivo de plantas arbóreas do Brasil. 5. ed. Nova Odessa (SP): Instituto Plantarum, 2008. v. 1, 384 p.

MILHEM, L. M. A.; MARINHO, C. S.; GUILHERME, D. O.; FREITAS, S. J.; FREITAS, J. A. A. Ambientes de enraizamento para goiabeiras propagadas por estaquia ou miniestaquia. Vértices, Campos dos Goytacazes. v. 16, n. 3, p. 75-85, set./dez. 2014. Disponível em: <http://essentiaeditora.iff.edu.br/ index.php/vertices/article/view/1809-2667.20140032>. Acesso em: 16 nov. 2015.

MORAES, A. F. de; APARECIDO, L. E. O.; PEREIRA, W. B. S. Reciclagem de garrafas pet na propagação de lichia e carambola. In: XV CONGRESSO NACIONAL DE MEIO AMBIENTE DE POÇOS DE CALDAS, 21 a 23 de maio de 2014. Anais... Disponível em: <https://www.google.com.br/?gfe_rd=$c r \& e i=X Z 5 x V r W B N Y y k 8 w e T r J D A A g \# q=R E C I C L A G E M+D E+G A R R A F A S+P E T+N A+P R O P A G A \%-$ C3\%87\%C3\%830+DE+LICHIA+E+CARAMBOLA>. Acesso em: 25 nov. 2015. 
MORAES, D. G. de; BARROSO, D. G.; FIGUEIREDO, F. A. M. M. A.; SILVA, T. R. C.; FREITAS, T. A. S. de. Enraizamento de miniestacas caulinares e foliares juvenis de Toona ciliata M. Roemer. Magistra, Cruz das Almas. v. 26, n. 1, p. 47 - 54, 2014. Disponível em: <file:///C:/Users/1673320/Downloads/06.042-12\%206\%202\%20(2).pdf>. Acesso em: 16 nov. 2015.

MOREIRA, C. V.; JOÃO, C. L.; CASSANJE, S. B.; CANDA, D. M.; SILVA, S. O.. Propagação do maracujazeiro amarelo em recipiente de poliestireno sob diferentes substratos. Magistra, v. 27, n. 1, p. 63 - 72, 2015. Disponível em: <file://C:/Users/1673320/Downloads/07-076-13\%20(1).pdf>. Acesso em: 25 nov. 2015.

REZENDE, O. P., PIMENTEL, L. D., AlVES, T. L., MORGADO, M. A. D.; NEVES L. G.; BRUCKNER, C. H. Estaquia de maracujá amarelo (Passiflora edulis Sims f.flavicarpa Deg.) em miniestufas constituídas de garrafas de poliestireno, avaliando-se cinco substratos. Revista Ceres, Lavras. v. 52, n. 300, p. 267-273, 2005. Disponível em: <http://www.ceres.ufv.br/ojs/index.php/ceres/article/viewFile/3043/927>. Acesso em: 25 nov. 2015.

SILVA, R. L. da; OLIVEIRA, M. L. de; MONTE, M. A.; XAVIER, A. Propagação clonal de guanandi (Calophyllum brasiliense) por miniestaquia. Agronomía Costarricense. San Pedro de Montes de Oca. v. 34, n. 1, p. 99-104, 2010. Disponível em: <http://www.scielo.sa.cr/pdf/ac/v34n1/a10v34n1. pdf $>$. Acesso em: 25 nov. 2015.

TRANNIN, I. C. B.; MOREIRA, F. M. S.; SIQUEIRA, J. O. Crescimento e nodulação de Acacia mangium, Enterolobium contortisiliquum e Sesbania virgata em solo contaminado com metais pesados. Revista Brasileira de Ciência do Solo, Viçosa, v. 25, n. 3, p.743-753, 2001. Disponível em: <http:// www.scielo.br/pdf/rbcs/v25n3/24.pdf>. Acesso em: 25 nov. 2015.

XAVIER, A.; SANTOS, G. A. dos; WENDLING, I.; OLIVEIRA, M. L. de. Propagação vegetativa de cedro-rosa por miniestaquia. Revista Árvore, Viçosa, v. 27, n. 2, p. 139-143, 2003a. Disponível em: <http://www.scielo.br/pdf/rarv/v27n2/15932.pdf>. Acesso em: 25 nov. 2015.

XAVIER, A.; SANTOS, G. A.; OLIVEIRA, M. L. de. Enraizamento de miniestaca caulinar e foliar na propagação vegetativa de cedro-rosa (Cedrela fissilis Vell.) Revista Árvore. Viçosa, v. 27, n. 3, p. 351-356, 2003b. Disponível em: <http://www.scielo.br/pdf/ rarv/v27n3/a11v27n3>. Acesso em: 25 nov. 2015.

XAVIER, A.; WENDLING, I; SILVA, R. L. da. Propagação Clonal pela Estaquia. In: Silvicultura clonal: princípios e técnicas. 2. ed. Viçosa: Editora UFV, 2009, p. 90 -143.

\section{Histórico editorial:}

Submetido em: 18/03/2016

Aceito em: 22/07/2016 
Como citar:

ABNT

FREITAS, T. A. S. de; PIMENTA, D. A. L.; MENDONÇA, A. V. R. Enraizamento de miniestacas de Enterolobium contortisiliquum em garrafas PET. Revista Agrogeoambiental, Pouso Alegre, v. 9, n. 3, p. 61-69, jul./set.

Doi: http://dx.doi.org/10.18406/2316-1817v9n32017968

$\underline{A P A}$

FREITAS, T. A. S. de, PIMENTA, D. A. L. \& MENDONÇA, A. V. R. (2017). Enraizamento de miniestacas de Enterolobium contortisiliquum em garrafas PET. Revista Agrogeoambiental, Pouso Alegre, 9 (3), 61-69.

Doi: http://dx.doi.org/10.18406/2316-1817v9n32017968

$\underline{\text { ISO }}$

FREITAS, T. A. S. de; PIMENTA, D. A. L. e MENDONÇA, A. V. R. Enraizamento de miniestacas de Enterolobium contortisiliquum em garrafas PET. Revista Agrogeoambiental, 2017, vol. 9, n. 3, pp. 61-69. Eissn 23161817.

Doi: http://dx.doi.org/10.18406/2316-1817v9n32017968

\section{VANCOUVER}

Freitas TAS de, Pimenta DAL, Mendonça AVR. Enraizamento de miniestacas de Enterolobium contortisiliquum em garrafas PET. Rev agrogeoambiental. 2017 jul/set; 9(3): 61-69.

Doi: http://dx.doi.org/10.18406/2316-1817v9n32017968 